\title{
Water quality and Sanitation status: A study on Char land of Bhuapur upazila under Tangail district
}

\author{
M. S. Islam ${ }^{1}$, B. C. Sarker ${ }^{1^{*}}$, N. A. Mahmud ${ }^{2}$ and A. S. M. Saifullah ${ }^{2}$ \\ ${ }^{1}$ Department of Environmental Science, Bangladesh Agricultural University, Mymensingh-2202, Bangladesh and \\ ${ }^{2}$ Department of Environmental Science and Resource Management, Mawlana Bhashani Science and Technology \\ University, Tangail-1902, Bangladesh, *E-mail: biddut_mbstu@yahoo.com
}

\begin{abstract}
The study was aimed to review the damage of sanitation facilities; since Char land's dwellers faces manifold challenges concerning sanitation, hygiene and water during flood. It also explored the possibilities of overcoming the negative impacts of floods on sources of safe drinking water and sanitation. The study result shows that, about $54 \%$ of the overall latrines were included ring slab with water seal, pit latrine, bush or hanging toilet of the flood affected people during the flood. Around 19\% of the respondents use to do toilet in the open area during flood. Different NGOs e.g. Jamuna Char Development Project (JCDP), Bangladesh Rural Advancement Committee (BRAC), CARE and Red Crescent Society of Bangladesh works for rehabilitation of the flood affected people and give early warning on the flood. Depending on location and sanitation conditions, drinking water sources may be contaminated by flood water during flood and many waterborne diseases can spread out like Cholera, Dysentery, Diarrhoea, diseases of the skin, Typhoid etc. meantime. The conducted survey also reports that, drinking water and sanitation condition is not dependable (on the commentary of $64.8 \%$ of the responders). Therefore, the flood affected people of Bhuapur are usually underprivileged from appropriate sanitation facility on flood. They somehow conform themselves while a chain of problems strikes hardly during flood.
\end{abstract}

Keywords: Drinking water, Flood, Char land, Sanitation, NGO

\section{Introduction}

Char land is the Bengali term for mid-channel island that emerges periodically from riverbed as a consequence of accretion (Elahi, 1991). In Bangladesh the char lands can be divided into five sub areas (the Jamuna, the Ganges, The Padma, The upper Meghna and the lower Meghna River) where Tista and old Brahmaputra also constitute some char land areas (Islam et al., 2012). The entire char land is unstable and prone to annual inundating (Roy et al., 2007). Every year flood occurs in Bangladesh as because, Bangladesh is a low laying area and it is situated nearby the Bay of Bengal. Besides this, some time it may remain long time and loss of property and life and damage the communication system. In Bangladesh the largest flood has been occurred in 1988 and in 1998 flood remain long period about six months when it has played a devastating role in the Char areas (Ministry of Water Resources, 2004). During and after flood sanitation condition breaks down and causes scarcity of drinking water as well. The high rate of incidence of diseases like Diarrohea and infant mortality in developing countries are attributed to lack of water supply and sanitation. Every year 3-million children (under 5 years of age) die of Diarrohea in developing countries. Every child in the third world countries suffers an average of three Diarrohea attacks a year. In Bangladesh, about $16 \%$ of the 90 million rural population use sanitary latrines. In addition, another $22 \%$ use the so-called homemade pit latrines that are constructed by placing a squatting slab made of bamboo over a manually dug pit. Many consider this homemade pit latrine as not fully sanitary (Ahmed et al. 2000). However, the quality of water is decreasing day by day due to various anthropogenic and natural activities all over the country. Especially in Tangail district the degradation of water quality is more significant. Surface water and Ground water are the sources of water that use in human consumption and other all activities in our country. Due to lack of safe drinking water various diseases occur (FPCO, 1994). Only 33\% of the households were found to have hygienic latrines while $25 \%$ have continue to use unhygienic ones. About 55 million people ( $42 \%$ households) do not use any form of latrine (BBS, 2007). The government has already taken the initiative to achieve their national sanitation target in collaboration with development partners and NGOs (National Sanitation Strategy, 2005). Safe drinking water and proper sanitation are essential for human health. Usually ground water is used for drinking purpose but during the flood ground may mix with flood water and becomes contaminated. Flood water also mixes with the human waste due to the poor sanitation system. By drinking this contaminated water many water borne diseases spreads out. Considering the aforementioned situation, this study was taken to evaluate water and sanitation status along with relevant health effects of the local people on Bhuapur upazila, Tangail. 


\section{Materials and Methods}

\section{Study Area}

The study was conducted at Bhuapur upazila under Tangail district. Bhuapur is an Upazila of Tangail District in the Division of Dhaka, Bangladesh and consists total area of $225.02 \mathrm{~km}^{2}$. Gabsara is one of the unions of Bhuapur out of 6 , which has total household 6183, total area 6771.64 hectares and total population 29438 (male 14141 and female 15297) (Banglapedia, 2008). This study is specially focused on Rulipara and Jongipur villages (Fig. 1). These villages are comparatively highly flood affected area in Gabsara union under Bhuapur upazila. Most of the people of this area are unconscious about health hazardous likely to happen during or after flood. In fact, they are not aware enough regarding this crucial issue unless they might have faced serious problems.
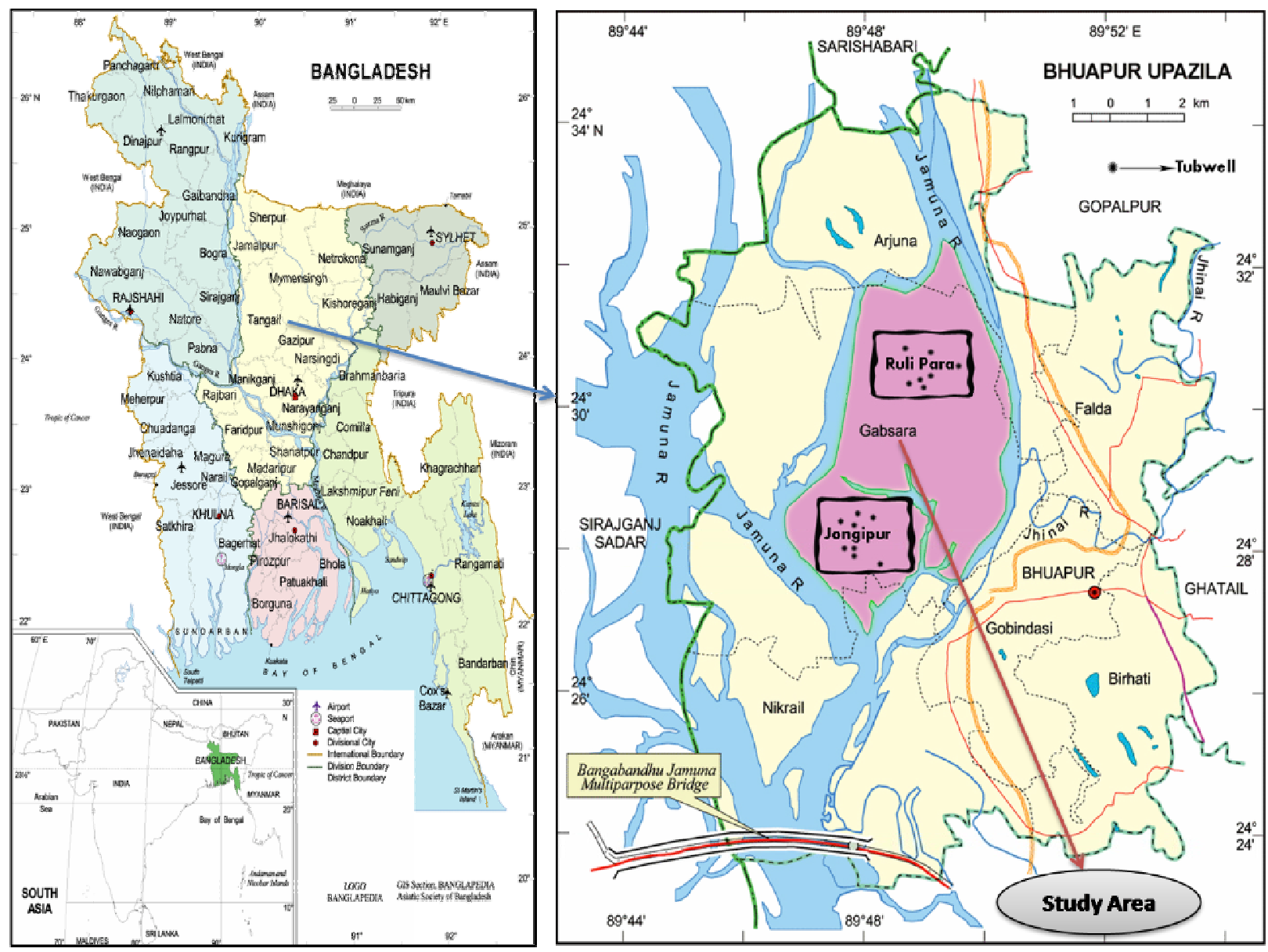

Fig. 1. Map showing the Study area (Source: Banglapedia, 2008).

\section{Research design and Data Collection}

The research was carried out on the bases of primary and secondary information. In this research, different methodologies as well as interview with local people, questionnaire, survey, Focus Group Discussion (FGD) and Participatory Reflection and Action (PRA) were applied for the collection of data. Data have been collected through interviewing technique through a questionnaire which include all essential questions those are relevant to the study. Both primary and secondary data was used for the study. Primary data was collected from the field level intrinsic study and realistic features are presented. 


\section{Sample Survey}

The study population was households having latrines with at least 3 rings and 1 slab. Having water seal was an operational criterion as its presence was not very common in the study area. Considering random sampling, the sample size was 54 households. The survey was conducted during the last week of the flood on September 2010.

\section{Data processing and analysis}

The collected data was "tabulated" and "coded". The SPSS (Statistical Package for Social Science) software and Microsoft office excel were used for analysis of data.

\section{Results and Discussion}

In the study, it was found that most of the respondents (5.6\%) were of age group 20-25 years followed by 26-35 years old (18.5\%). The highest (64.8\%) numbers of respondents were of above 46 years. The study also revealed that, most of the respondents (75.9\%) were male and $24.1 \%$ are female. The study indicates that, more than half of the respondents (55.6\%) were illiterate or no schooling, 29.6 percent of the respondents were primary level educated, 11.1 percent had secondary level of education, 1.9 percent respondents having the higher secondary level and Graduation (Table 1).

Table 1. Profile of the respondents $(\mathrm{N}=54)$

\begin{tabular}{|c|c|c|c|}
\hline Variable & Percentage & Variable & Percentage \\
\hline \multicolumn{2}{|c|}{ Sex } & \multicolumn{2}{|c|}{ Education } \\
\hline Male & 75.9 & No Schooling & 55.6 \\
\hline Female & 24.1 & Primary & 29.6 \\
\hline Total & 100 & SSC & 11.1 \\
\hline \multicolumn{2}{|c|}{ Occupation } & $\mathrm{HSC}$ & 1.9 \\
\hline Farmer & 59.3 & Graduate & 1.9 \\
\hline Housewife & 22.2 & total & 100 \\
\hline Businessman & 5.6 & \multicolumn{2}{|c|}{ Age } \\
\hline Student & 3.7 & $20-25$ & 5.6 \\
\hline Others & 9.3 & $26-35$ & 18.5 \\
\hline \multirow[t]{3}{*}{ Total } & 100 & $36-45$ & 11.1 \\
\hline & & 46 above & 64.8 \\
\hline & & Total & 100.0 \\
\hline
\end{tabular}

The occupation of the respondent it is revealed that, 59.3, 22.2, 5.6 and 3.7 percent of the respondents were farmer, housewife, business man and student respectively, besides this others respondents were of 9.3 percent. Most of the respondents' per month income were less than 5000 (Table 1).

Following Fig. 2 shows that, 87 percent of the respondents were fully depended on ground water through tube-well, 11.1 percent respondents depended on river water and the rest 1.9 percent of the respondent depended on pond water for drinking water.

Existing drinking water and sanitation provision of affected area (Fig. 3) showed that, most of the respondents (77.8\%) thought tube well water is safe for drinking during and after flood and rest respondents thought, it was not healthy for drinking due to intrusion of pollutants. Hence, it is their wrong perception regarding the matter because a tube well might be free from contamination if it is out of the flood water. On the contrary, it can be affected by not only in submerged condition of tube well but also through water table. 


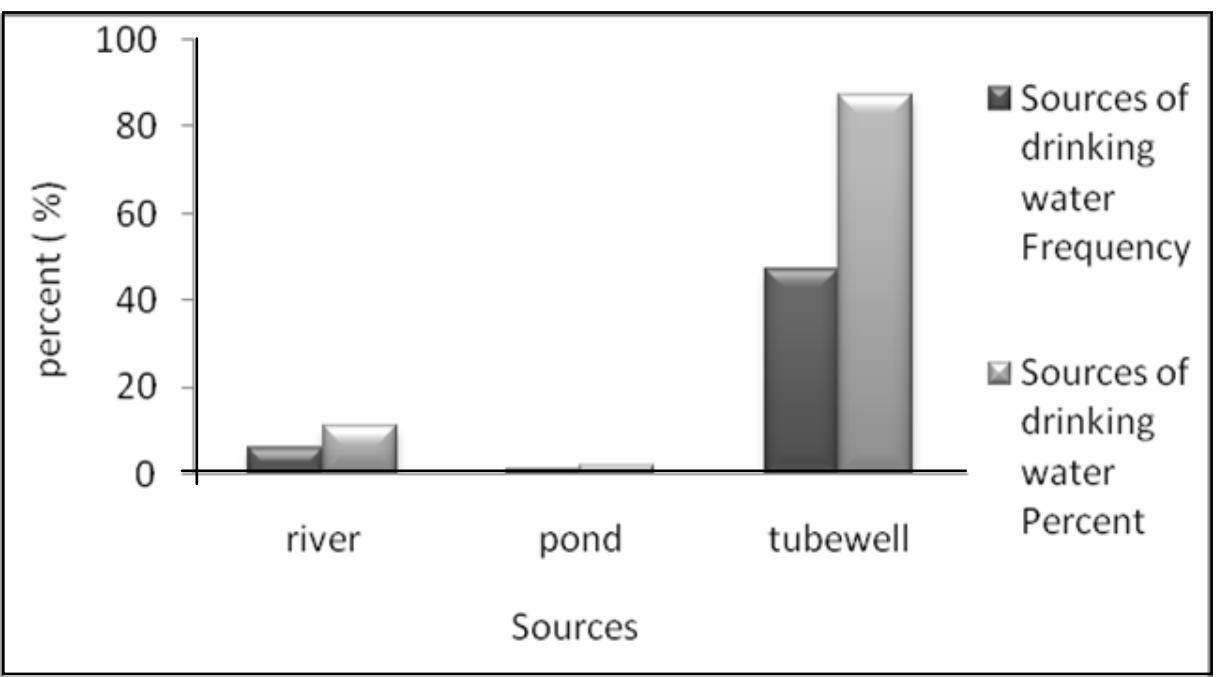

Fig. 2. Sources of the drinking water

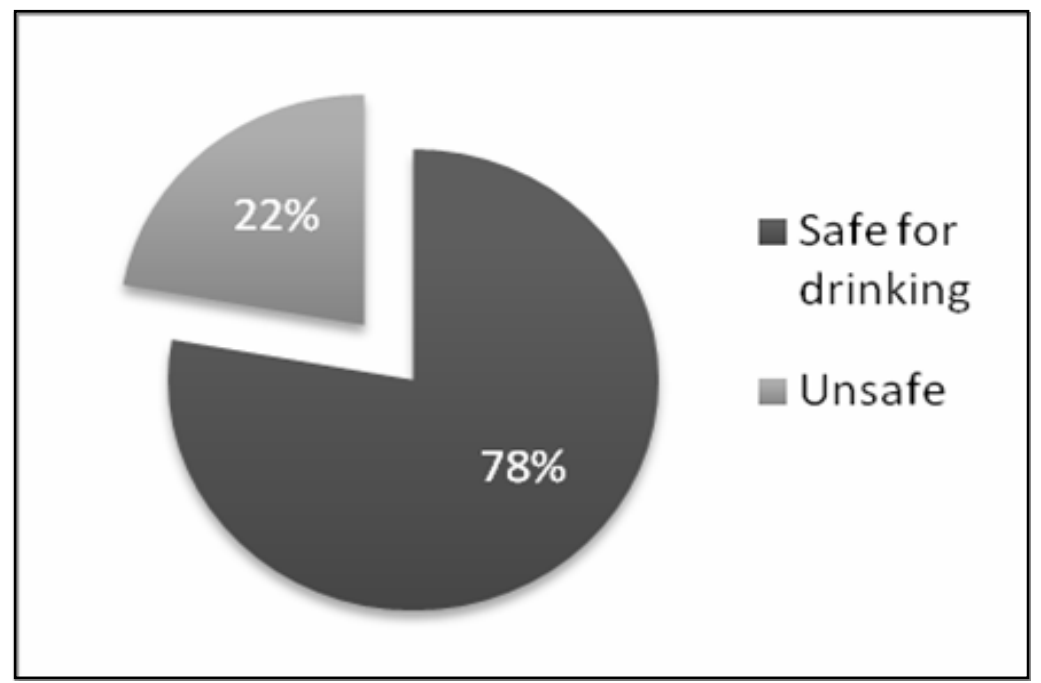

Fig. 3. Safety-net of tube well water for drinking purpose on the commentary of respondent

Flood affected people used some procedure to make water safe for drinking such as boiling, filtering, using chlorine tablet given by Govt. and Non- Governmental organizations and beside this other people used to take the unsafe drinking water as they could not access the facility properly and therefore they were usually affected by different types of water born diseases. Majority of the respondents were worst sufferer by the impact of flood on drinking water and sanitation during and after flood.

In the study it was found that (Fig. 4), most of the respondents had toilet of their own and more than half of the respondents (57.4\%) used ring slab with water seal toilet, $7.4 \%$ used pit latrine, $11.1 \%$ used hanging toilet, $5.6 \%$ used bush toilet and rest of the respondents used open field. People's satisfaction on existing provision of water and sanitation facility is mentioned with Fig. 5 with the following.

Result revels that, respondents were not satisfied of their water and sanitation facility and only about $1.9 \%$ respondents were satisfied, $33.3 \%$ possessed average and $64.8 \%$ bad level of satisfaction regarding this matter all of them deserve proper quality water and sanitation facility during and after flood. 


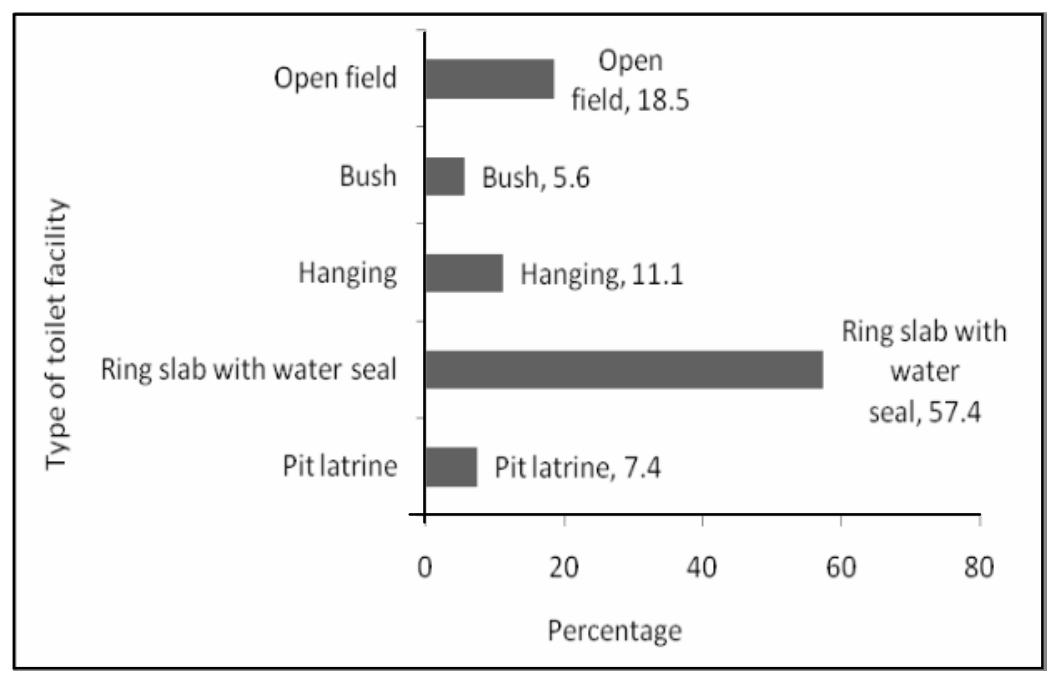

Fig. 4. Sanitation status of affected area

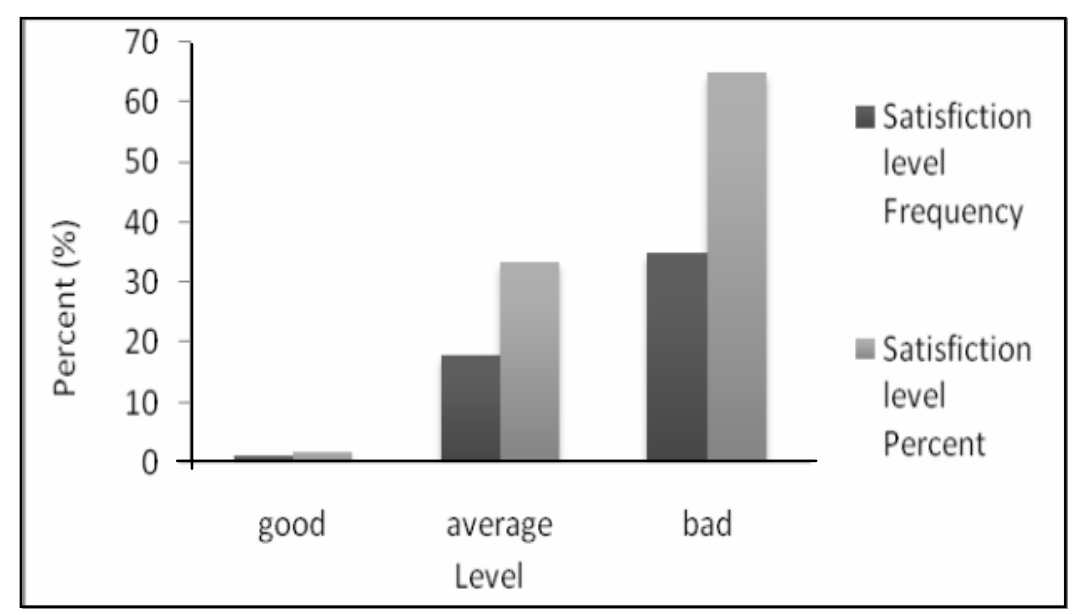

Fig. 5. Satisfaction level of Water and Sanitation facility

The aforementioned Fig. 6 shows that, most of the respondents (85\%) got early warning about flood with their indigenous knowledge and rest of the respondents got early warning about flood after flood forecasting from meteorological department. The study also found that, different non-Governments agencies work for rehabilitation of the flood affected people during and after flood beside the Governmental agencies. Most of the respondents (76\%) do not get rehabilitation facility during and after flood and they suspect the management and faulty distribution system of relief and goods allotted for them.

Under mentioned Fig. 7 reveals that, majority of the respondents (88.9\%) suffered from water borne diseases during and after flood. Different types of diseases outbreak as the resulting effects of flood, where skin diseases, Diarrhoea, Cholera, and Typhoid are remarkable. 


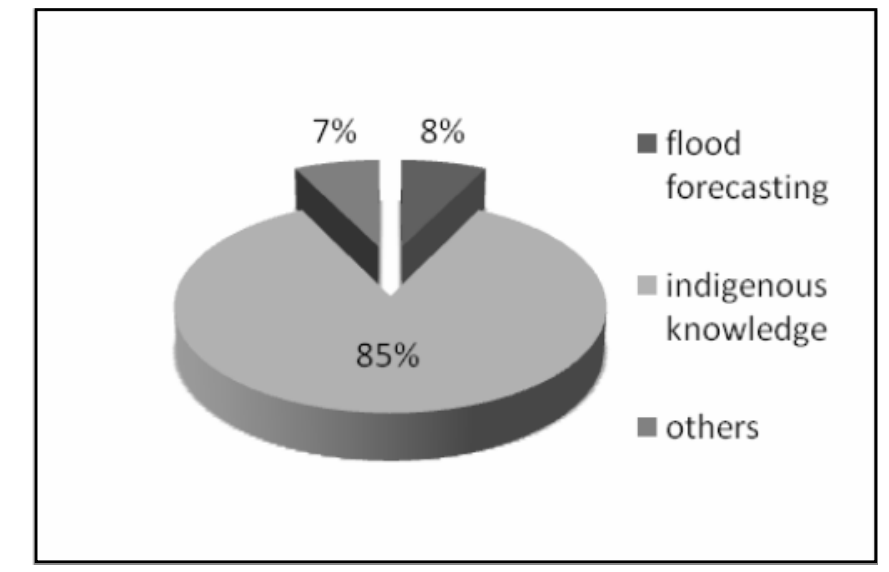

Fig. 6. Provision of having early warning about flood

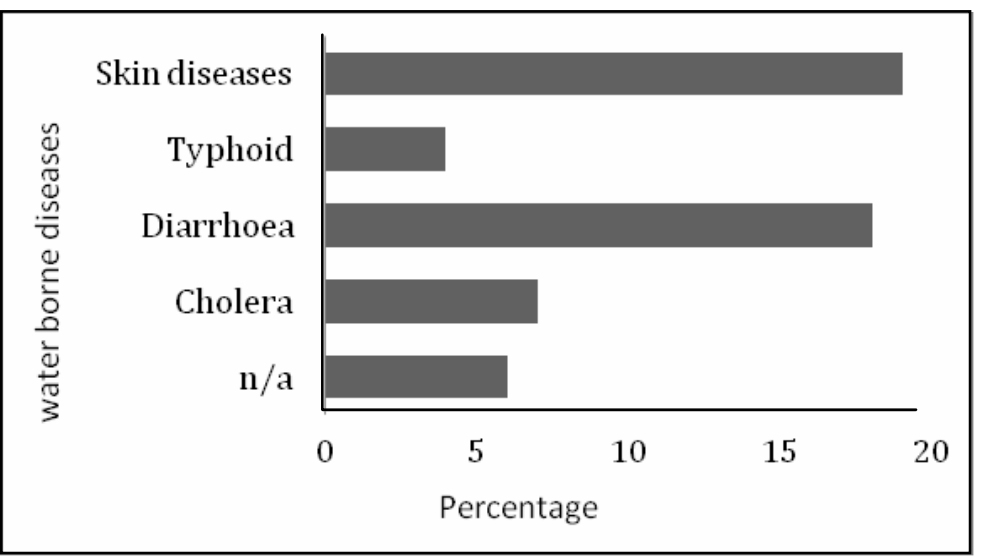

Fig. 7. Sufferings due to water borne diseases

\section{Conclusion}

Char land people of Bhuapur Upazila are suffering from inadequate water and sanitation problem during and after flood likewise there is scarcity of safe drinking water. More than half of the total flood affected people are seriously vulnerable due to lack of safe drinking water and sanitation facility. Monitoring program to preclude possible problems regarding water and sanitation of the flood affected area is needed. Government and non-government agencies had better step forward for the improvement of rehabilitation system or adaptive capacity, relief donation, pure water supply of living people and elevated latrines to improve the sanitation condition during flood.

\section{References}

Ahmed, M., Feroze, F. and Rahman, M.M. 2000. Water Supply and Sanitation-Rural and Low Income Urban Communities, ITNBangladesh, BUET, Dhaka, Bangladesh.

Bangladesh Bureau of Statistics (BBS). 2007. Report on the household income and expenditure survey of 2005, Dhaka, Bangladesh.

Banglapedia. 2008. National Encyclopedia of Bangladesh, Asiatic Society of Bangladesh.

Elahi, K.M. 1991. Impacts of riverbank erosion and flood in Bangladesh: An introduction. Riverbank Erosion Impact Study, Jahangirnagar University, Dhaka, p.11-67.

Flood Plan Coordination Organization (FPCO). 1994. Flood Action Plan, Ministry of Water resource, Govt. of Bangladesh.

Islam, M.S., Hasan, T., Chowdhury, M.S.I.R., Rahaman, M.H. and Tusher, T.R. 2012. Coping Techniques of Local People to Flood and River Erosion in Char Areas of Bangladesh, J. Environ. Sci. \& Natural Resources, 5(2): 251 - 261.

Ministry of Water resources. 2004. Bangladesh Floods, Govt. of Bangladesh.

National Sanitation Strategy. 2005. Ministry of Local Government, Rural Development and Cooperatives, People's Republic of Bangladesh.

Roy, M.K., Syed, S.U.I. and Azim, A. 2007. Settlement of a char land Community: A Study on Social Crisis and Coping Pattern, in seminar organized Bangladesh Economic Association, Dhaka, Bangladesh. 